\title{
Development, validity, and reliability of a Japanese version of End-of-Life in Dementia scales
}

\section{Sayaka Toya ( $\nabla$ toya-sayaka@gchs.ac.jp )}

Gunma Prefectural College of Health Sciences

\section{Yoko Uchida}

Gunma University

\section{Tsuneo Yamazaki}

Gunma University

\section{Tomoyuki Saito}

Yokohama City University Graduate School of Medicine

\section{Yuhei Chiba}

Sekiaikai Yokohama Maioka Hospital

\section{Tomoyuki Kawashima}

Gunma University

\section{Yukari Takai}

Gunma Prefectural College of Health Sciences

\section{Haruyasu Yamaguchi}

Tokyo Center for Dementia Care Research and Practices

\section{Research Article}

Keywords: Dementia, End-of-life care, Older adult, Palliative care, Nursing home, Scale

Posted Date: February 14th, 2022

DOI: https://doi.org/10.21203/rs.3.rs-827472/v2

License: (c) (1) This work is licensed under a Creative Commons Attribution 4.0 International License.

Read Full License 


\section{Abstract}

Background: End-of-life care quality should ideally be evaluated by patients themselves. However, patients suffer clinical symptoms and conspicuous cognitive and physical decline in end-stage dementia. Therefore, family members and nurses are often good proxies for evaluating patients' satisfaction with end-of-life care and symptoms in end-stage dementia. The End-of-Life in Dementia scales, originally written in English, were specifically designed to examine the quality of end-of-life care for persons with dementia. This study aimed to develop a Japanese version of the End-of-Life in Dementia scales and evaluate its validity and reliability in Japan.

Methods: The Japanese version of the End-of-Life in Dementia scales (EOLD-J) was created by translating the following original scale measurements: Satisfaction with Care (SWC-EOLD-J), Symptom Management (SM-EOLD-J), and Comfort Assessment in Dying with dementia (CAD-EOLD-J). Participants were 113 family members of deceased residents who received end-of-life care and died at 33 participating nursing homes, and 113 nurses who provided care to the residents. Participants were asked to recall the residents' last months and respond using the designated scales. The reliability of the scales was evaluated using a Cronbach's alpha. The construct validity of the relationships between the SWCEOLD-J scores and the Japanese Decision Regret Scale (DRS-J), the SM-EOLD-J and the short version of Quality of Life Questionnaire for Dementia (short QOL-D), and the CAD-EOLD-J and the short QOL-D were evaluated using Spearman's rank correlation coefficient. The short QOL-D is composed of positive and negative dimensions.

Results: Responses from 83 deceased residents' family members, and 62 nurses were analyzed. The Cronbach's alphas of the SWC-EOLD-J was 0.77, the SM-EOLD-J was 0.60, and the CAD-EOLD-J was 0.88 . The SWC-EOLD-J score was significantly correlated with DRS-J ( $(\$ 0.504, p<0.001)$. The SM-EOLD-

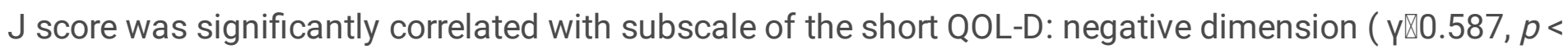
0.001), the CAD-EOLD-J score was significantly correlated with subscale of the short QOL-D: negative dimension $(\gamma \otimes 0.509, p<0.001)$.

Conclusions: This study developed the EOLD-J and confirmed the reliability and validity of this scale.

\section{Background}

The number of persons with dementia worldwide is estimated to reach 82 million in 2030 (1), and has been increasing in Japan's super-aging society (2). A 2010 survey estimated that the daily lives of 4.6 million older Japanese individuals were affected by dementia (3). Dementia is a progressive terminal disease, and as symptoms progress, older persons with dementia often need suitable end-of-life care (4). In Japan, approximately $36 \%$ of persons with dementia reside in nursing homes (3). Furthermore, according to the results of a previous study that investigated the place of death of older people with dementia in Japan, $32 \%$ of people with dementia died in nursing homes (5). Therefore, there is a need to provide appropriate end-of-life care to residents; in order to improve the quality of end-of-life care, it 
should be monitored and evaluated. Consequently, appropriate end-of-life care for residents and care evaluation methods are highly required.

End-of-life care quality should ideally be evaluated by persons with dementia themselves. However, clinical symptoms and conspicuous cognitive and physical decline in end-stage dementia make it difficult for older persons with dementia to evaluate end-of-life care by themselves and express their will and symptoms $(6,7)$. Family members are often good proxies for evaluating satisfaction with end-of-life care.

Nurses should be responsible for examining the conditions of persons with dementia and providing endof-life care to these patients in Japanese nursing homes $(8,9)$. Although there is a small number of nurses compared to care workers at Japanese nursing homes (10), nurses need to properly examine endof-life care using scales evaluated for reliability and validity. Thus, there is a need for an end-of-life care quality assessment scale relevant to people with end-stage dementia that can be conducted by nurses.

Scales available in Japan to evaluate end-of-life care include the Good Death Inventory and the Japanese version of the Support Team Assessment Schedule (STAS-J). The Good Death Inventory was developed to objectively assess the quality of end-of-life care provided to cancer patients (11). Nurses in hospice and palliative care wards could use the STAS-J (12) to evaluate the efficacy of care in hospice and palliative care wards. However, it is difficult to the find the Japanese version of end-of-life care assessment scales that is specific to measure quality of care for older adults with dementia in the nursing homes.

The End-of-Life in Dementia (EOLD) scales were written in English and specifically designed to examine the quality of end-of-life care for persons with dementia $(13,14)$. The EOLD scales allows family members and care providers as a proxy to objectively evaluate end-of-life care for persons with severe dementia, which is difficult to evaluate subjectively. Furthermore, it could be suitable for measurement not only in hospitals but also in elderly care facilities. The scales consist of three parts that measure the following outcomes: Satisfaction With Care at end-of-life in dementia (SWC-EOLD) evaluated by bereaved family members of deceased residents, Symptom Management at end-of-life in dementia (SM-EOLD), and Comfort Assessment in Dying with dementia (CAD-EOLD), evaluated by nurses. The reliability and validity of the SM-EOLD and CAD-EOLD among nurses in nursing homes have been examined in a previous study (15); however, they have not been examined in the Japanese context. Therefore, the development of the Japanese version of EOLD (EOLD-J) scales could be beneficial to facilitate end-of-life care and improve quality of care in nursing homes. The purpose of the current research was therefore to develop the EOLD-J scales by verifying their reliability and validity in Japanese nursing homes.

\section{Methods}

Development of the EOLD-J Scales 
Consent for the development of the EOLD-J scales was obtained from authors of the original EOLD scales $(13,14)$. We also obtained permission from Saito et al. $(16)$, who developed a Japanese version of the scale in 2013 but did not validate it. To evaluate face validity, five researchers in care for older adults were consulted about whether the contents of the scales could be useful in Japanese nursing homes. We modified the Saito et al. (16) version by changing the word "patient" to "care recipient", among other changes. Nurses in Japanese nursing homes were asked to use the modified EOLD-J scales to confirm their ease of completion and that the scales would be useful for nurses to measure the quality of end-oflife care. The nurses confirmed that the scale was understandable to family caregivers. Subsequently, two professional translators with no prior knowledge of the current scale performed back-translation of the EOLD-J scales. The authors of the original EOLD scales evaluated the back-translation, and necessary modifications were made, based on their comments. Following their approval, the EOLD-J scales were considered complete.

Configuration of EOLD-J Scales

The SWC-EOLD-J is used to assess satisfaction with care and involvement in the decision-making process, based on family members' responses (15). It consists of 10 items, measured on a 4-point Likert scale ranging from 1 (strongly disagree) to 4 (strongly agree), with higher scores indicating greater satisfaction (15).

The SM-EOLD-J with physical and psychological symptom subscales quantifies the frequency of nine symptoms and signs, such as "shortness of breath," "skin breakdown," and "resistiveness to care" (15), as assessed by the nurses who care for residents. The frequency was quantified on a 6-point Likert scale ranging from 0 (every day) to 5 (never), with higher scores indicating better symptom control (15).

Meanwhile, the CAD-EOLD-J comprised 14 symptoms, including pain and difficulty in swallowing, and conditions such as "serenity (inner peace)" and "peace" (15), as assessed by the nurses. These items were rated from 1 (a lot) to 3 (not at all) with higher scores indicating better symptom control (15). The CAD-EOLD-J consists of four subscales: Physical Distress, Dying Symptoms, Emotional Distress, and Well-Being (15).

Participating Facilities and Participants

Participating facilities were nursing homes in Japan that provided end-of-life care for older residents with dementia during the past year. We sent letters to the directors of the facilities in two prefectures. Thirtythree nursing homes agreed to participate in the study.

Participants were family members/guardians of the deceased persons with dementia (residents), who were involved in decision-making on behalf of the persons with dementia, along with one nurse for each patient who provided end-of-life care. Inclusion criteria of deceased residents were those who received diagnoses of dementia, were provided end-of-life care, and died at the facilities (more than three months but less than two years prior to this study). 


\section{Data Collection Procedure}

Self-report questionnaires were distributed to 113 family members of deceased residents and 113 nurses, and were returned by mail. This study was conducted from April 2017 to December 2019.

\section{Instruments}

To collect background information on deceased residents, nurses from participating facilities were asked to verify medical and care records and provide information about residents' age at death and gender. They were also asked to complete the Functional Assessment Staging of Alzheimer's Disease scale (FAST) (17) to identify the degree of dementia and cause of death.

Family members of deceased residents were asked about their age, gender, and relationship with residents, and then asked to complete the SWC-EOLD-J and Japanese Decision Regret Scale (DRS-J) (18) regarding the end-of-life care provided in the month prior to death. The DRS-J is a self-administered assessment scale composed of five items with Likert-type responses from 1 (strongly agree) to 5 (strongly disagree). Higher scores indicate greater regret (18). The SWC-EOLD-J includes several assessment items related to support for decision-making, and the SWC-EOLD-J score was considered to be related to the DRS-J score.

Nurses were asked to complete the SM-EOLD-J, CAD-EOLD-J, and the Short Version of the Quality of Life Questionnaire for Dementia (short QOL-D) (19). The short QOL-D was used to review care records from one month prior to the resident's death. There are two dimensions in the short QOL-D (positive dimensions: 6 items, negative dimensions: 3 items) with responses rated on a four-point Likert-type scale ranging from 1 to 4 . Accordingly, the positive dimension is evaluated based on participants" well-being and is determined by considering the behavior of the person with dementia. It includes statements such as "enjoys seeing other people's activities" (19). In contrast, the negative dimension is evaluated based on the psychological symptoms of people with dementia, including items involving being "quick-tempered," "hits or kicks things," and "shouts loudly" (19). The nurses were also asked about their age, gender, years of nursing experience, and years of experience at the current facility.

\section{Ethical Considerations}

A written informed consent for participation in this study and for the use of the deceased resident's data was obtained from the family members of deceased residents, as well as participating nurses. Documents sent to the participants explained the purpose of the research, informed them about the voluntary nature of participation, the fact that withdrawal from the research would cause no disadvantage to them, and the research methods, and reassured the promise of confidentiality and protection of personal information. Research procedures were conducted with the approval of the School of Medicine Research Ethics Committee (Examination number HS2018-199) governing Gunma University affiliates, and that of the management of participating facilities. This study was conducted in accordance with the principles of the Declaration of Helsinki. 


\section{Data Analysis}

Samples without missing values were used in this study. Cronbach's alpha for each of the scales (SWCEOLD-J, SM-EOLD-J, and CAD-EOLD-J) was calculated to evaluate reliability.

The Spearman's rank correlation coefficient was calculated for compared scores between SWC-EOLD-J and DRS-J. As a hypothesis for these variables, we predicted that those with less regret about their family members decisions regarding end-of-life care would be more satisfied with the EOLC that their residents received; and the result show negative correlation. The Spearman's rank correlation coefficient was calculated to compare the SM-EOLD-J and short QOL-D scores and the CAD-EOLD-J and short QOL-D scores. As a hypothesis for these variables, we predicted that deceased residents who had a high QOL rating would have fewer distressing symptoms before death and would be rated as having led a more comfortable life. These were conducted to evaluate convergent validity, which is a verification of construct validity (Figure 1). The Spearman's rank correlation coefficient for total scores between scales was also calculated. An exploratory factor analysis was conducted using the principal factor method and varimax rotation to verify structural validity. The number of factors was determined after checking the eigenvalues and scree plots. We adopted the criterion that to be significant, the loadings must be greater than 0.4 (20). All data were analyzed using IBM SPSS 24. Further confirmatory factor analysis was conducted to test the model fit of the subscales. The criteria for model fit are goodness of fit index (GFI), comparative fit index (CFI) of 0.9 or higher and root mean square error of approximation (RMSEA) of 0.8 or lower (21). The analysis was performed using IBM SPSS Amos Version 27.0.

\section{Results}

\section{Characteristics of Research Participants}

Questionnaires were sent to 113 family members and 113 nurses, out of which, 92 family members $(81.4 \%)$ and 90 nurses $(79.7 \%)$ returned responses to researchers. The deceased residents with the Functional assessment staging of Alzheimer's disease (FAST) stages ranging from one to three $(n=3)$ and those with incomplete questionnaires $(n=20)$ were excluded. Finally, we analyzed the responses with no missing values from 85 family members $(75.2 \%)$ and 62 nurses $(54.9 \%)$. The basic attributes of participants are shown in Table 1. 
Table 1. Basic attributes of participants

\begin{tabular}{|c|c|c|c|c|c|c|}
\hline Participant & Item & & $n$ & $\%$ & Mean & SD \\
\hline \multirow{9}{*}{$\begin{array}{l}\text { Deceased } \\
\text { Resident }\end{array}$} & Age at death & & 85 & & 91.4 & 6.60 \\
\hline & Gender & Female & 62 & 72.9 & & \\
\hline & & Male & 23 & 27.1 & & \\
\hline & FAST† & Stage 4 & 7 & 6.2 & & \\
\hline & & Stage 5 & 12 & 14.1 & & \\
\hline & & Stage 6 & 23 & 27.1 & & \\
\hline & & Stage 7 & 43 & 50.6 & & \\
\hline & Cause of death & Senility & 64 & 79.0 & & \\
\hline & & Others & 21 & 21.0 & & \\
\hline \multirow[t]{10}{*}{ Family $\ddagger$} & Age & & 85 & & 65.0 & 8.78 \\
\hline & Gender & Female & 48 & 56.7 & & \\
\hline & & Male & 37 & 43.5 & & \\
\hline & $\begin{array}{l}\text { Relationships with } \\
\text { residents }\end{array}$ & Spouse & 4 & 4.7 & & \\
\hline & & Sibling & 1 & 1.2 & & \\
\hline & & Child & 67 & 78.8 & & \\
\hline & & $\begin{array}{l}\text { Child of } \\
\text { spouse }\end{array}$ & 8 & 9.4 & & \\
\hline & & Grandchild & 1 & 1.2 & & \\
\hline & & Others & 4 & 4.7 & & \\
\hline & Years of nursing care & & 85 & & 8.2 & 5.08 \\
\hline \multirow[t]{5}{*}{ Nurse } & Age & & 61 & & 51.2 & 11.32 \\
\hline & Gender & Female & 58 & 93.5 & & \\
\hline & & Male & 4 & 6.5 & & \\
\hline & $\begin{array}{l}\text { Years of nursing } \\
\text { experience }\end{array}$ & & 62 & & 25.7 & 12.39 \\
\hline & $\begin{array}{l}\text { Years of working at the } \\
\text { facility }\end{array}$ & & 62 & & 8.7 & 5.06 \\
\hline
\end{tabular}


Table 1. Basic attributes of participants

†FAST:Functional assessment staging of Alzheimer's disease

łFamily:Family members of the deceased residents

SWC-EOLD-J

Scores for each part of the SWC-EOLD-J scales and DRS-J are shown in Table 2. The Cronbach's alpha of the SWC-EOLD-J rated by family members of the deceased residents was $0.77(n=83)$.

Results of the convergent validity testing are presented in Table 3. The SWC-EOLD-J score was significantly moderately correlated with the DRS-J score $(Y=-0.504, p<0.001)$. 
Table 2

Score of SWC-EOLD-J scales and DRS-J

\begin{tabular}{|c|c|c|c|c|c|}
\hline Scale & Respondent & Item & Range & Mean & $S D$ \\
\hline $\begin{array}{l}\text { The SWC- } \\
\text { EOLD-Jt }\end{array}$ & Family $\ddagger$ & $\begin{array}{l}\text { I felt fully involved in all decision-making } \\
\text { processes. }\end{array}$ & $1-4$ & 3.30 & 0.60 \\
\hline \multirow[t]{10}{*}{$(n=83)$} & & $\begin{array}{l}\text { I probably would have made different } \\
\text { decisions if I had more information*. }\end{array}$ & $1-4$ & 3.24 & 0.60 \\
\hline & & $\begin{array}{l}\text { All measures were taken to keep my care- } \\
\text { recipient comfortable. }\end{array}$ & $1-4$ & 3.35 & 0.50 \\
\hline & & $\begin{array}{l}\text { The healthcare team was sensitive to my } \\
\text { needs and feelings. }\end{array}$ & $1-4$ & 3.41 & 0.61 \\
\hline & & $\begin{array}{l}\text { I did not really understand my care- } \\
\text { recipient's condition*. }\end{array}$ & $1-4$ & 3.30 & 0.64 \\
\hline & & $\begin{array}{l}\text { I always knew which doctor or nurse was } \\
\text { in charge of my care-recipient's care. }\end{array}$ & $1-4$ & 3.23 & 0.63 \\
\hline & & $\begin{array}{l}\text { I feel that my care-recipient got all } \\
\text { necessary nursing assistance. }\end{array}$ & $1-4$ & 3.45 & 0.59 \\
\hline & & $\begin{array}{l}\text { I felt that all medication issues were } \\
\text { clearly explained to me. }\end{array}$ & $1-4$ & 3.11 & 0.52 \\
\hline & & $\begin{array}{l}\text { My care-recipient received all treatments or } \\
\text { interventions that he or she could have } \\
\text { benefited from. }\end{array}$ & $1-4$ & 3.28 & 0.57 \\
\hline & & $\begin{array}{l}\text { I feel that my care-recipient needed better } \\
\text { medical care at the end of his or her life*. }\end{array}$ & $1-4$ & 2.88 & 0.97 \\
\hline & & Total & $\begin{array}{l}10- \\
40\end{array}$ & 32.54 & 3.60 \\
\hline The DRS-J\| & Family $\ddagger$ & Total & $\begin{array}{l}0- \\
100\end{array}$ & 14.53 & 13.77 \\
\hline \multicolumn{6}{|l|}{$(n=83)$} \\
\hline \multicolumn{6}{|c|}{ łFamily: Family members of the deceased residents, } \\
\hline \multicolumn{6}{|c|}{$\begin{array}{l}\text { †The SWC-EOLD-J: Japanese version of satisfaction with care at the end- } \\
\text { of-life in dementia }\end{array}$} \\
\hline \multicolumn{6}{|c|}{$\begin{array}{l}\text { \|The DRS-J: Japanese } \\
\text { decision regret scale }\end{array}$} \\
\hline $\begin{array}{l}\text { *Reverse cod } \\
\text { calculation o } \\
\text { score. }\end{array}$ & $\begin{array}{l}\text { for } \\
\text { he total }\end{array}$ & & & & \\
\hline
\end{tabular}


Table 3

Correlation between the EOLD-J scales and the DRS-J/short QOL-D

\begin{tabular}{|c|c|c|c|c|c|c|}
\hline & \multicolumn{2}{|c|}{$\begin{array}{l}\text { The SWC-EOLD- } \\
\text { Jt }\end{array}$} & \multicolumn{2}{|c|}{ The SM-EOLD-J‡ } & \multicolumn{2}{|c|}{ The CAD-EOLD-J§ } \\
\hline Respondent & \multicolumn{2}{|l|}{ Family 9} & \multicolumn{2}{|l|}{ Nurse } & \multicolumn{2}{|l|}{ Nurse } \\
\hline \multirow[t]{2}{*}{$n$} & \multicolumn{2}{|l|}{83} & \multicolumn{2}{|l|}{55} & \multicolumn{2}{|l|}{55} \\
\hline & Y & $p$ & Y & $p$ & Y & $p$ \\
\hline DRS-J\| & $-0.504^{\star}$ & $<0.001$ & & & & \\
\hline short QOL-D\# & & & -0.238 & 0.080 & -0.187 & 0.177 \\
\hline \multicolumn{7}{|l|}{ Positive dimension } \\
\hline $\begin{array}{l}\text { short QOL-D\# Negative } \\
\text { dimension }\end{array}$ & & & $0.587 *$ & $<0.001$ & $0.509 *$ & $<0.001$ \\
\hline short QOL-D\# Total & & & 0.089 & 0.519 & 0.101 & 0.466 \\
\hline \multicolumn{7}{|c|}{$\begin{array}{l}\text { * } \mathbb{L} 0.001 \text {. Spearman rank correlation } \\
\text { coefficient. }\end{array}$} \\
\hline \multicolumn{7}{|c|}{$\begin{array}{l}\text { 9Family: Family members of the deceased } \\
\text { residents }\end{array}$} \\
\hline \multicolumn{7}{|c|}{$\begin{array}{l}\text { †The SWC-EOLD-J: Japanese version of satisfaction with care at the end-of-life in } \\
\text { dementia }\end{array}$} \\
\hline \multicolumn{7}{|c|}{$\begin{array}{l}\text { ‡The SM-EOLD-J: Japanese version of symptom management at the end-of-life in } \\
\text { dementia }\end{array}$} \\
\hline \multicolumn{7}{|c|}{$\S$ \The CAD-EOLD-J: Japanese version of comfort assessment in dying with dementia } \\
\hline \multicolumn{7}{|c|}{ ||The DRS-J: Japanese Decision Regret Scale } \\
\hline $\begin{array}{l}\text { \#The short QOL-D: shor } \\
\text { dementia }\end{array}$ & sion of & qualit & quest & aire for & & \\
\hline
\end{tabular}

\section{$S M-E O L D-J$}

Scores for each part of the SM-EOLD-J scales and short QOL-D are shown in Table 4. The Cronbach's alpha for the SM-EOLD-J among nurses was $0.80(n=62)$. The Cronbach's alpha for the SM-EOLD-J subscales of physical and psychological symptoms was 0.58 and 0.82 , respectively. 
Table 4

Score of SM-EOLD-J, CAD-EOLD-J scales and short QOL-D

\begin{tabular}{|c|c|c|c|c|c|}
\hline Scale & Respondent & Item & Range & Mean & SD \\
\hline The SM-EOLD-J§ & Nurse & Pain & $0-5$ & 3.39 & 2.00 \\
\hline \multirow[t]{9}{*}{$(n=62)$} & & Shortness of breath & $0-5$ & 3.32 & 2.01 \\
\hline & & Skin breakdown & $0-5$ & 3.81 & 1.85 \\
\hline & & Calm* & $0-5$ & 4.05 & 1.69 \\
\hline & & Depression & $0-5$ & 4.15 & 1.54 \\
\hline & & Fear & $0-5$ & 4.47 & 1.28 \\
\hline & & Anxiety & $0-5$ & 3.81 & 1.81 \\
\hline & & Agitation & $0-5$ & 4.11 & 1.69 \\
\hline & & Resistiveness to care & $0-5$ & 3.97 & 1.74 \\
\hline & & Total & $0-45$ & 35.06 & 9.80 \\
\hline The CAD-EOLD-Jq & Nurse & Discomfort & $1-3$ & 2.44 & 0.62 \\
\hline \multirow[t]{14}{*}{$(n=62)$} & & Pain & $1-3$ & 2.44 & 0.64 \\
\hline & & Restlessness & $1-3$ & 2.56 & 0.67 \\
\hline & & Shortness of breath & $1-3$ & 2.39 & 0.69 \\
\hline & & Choking & $1-3$ & 2.66 & 0.54 \\
\hline & & Gurgling & $1-3$ & 2.31 & 0.69 \\
\hline & & Difficulty swallowing & $1-3$ & 1.61 & 0.61 \\
\hline & & Fear & $1-3$ & 2.69 & 0.56 \\
\hline & & Anxiety & $1-3$ & 2.58 & 0.59 \\
\hline & & Crying & $1-3$ & 2.74 & 0.54 \\
\hline & & Moaning & $1-3$ & 2.68 & 0.57 \\
\hline & & Serenity* & $1-3$ & 2.39 & 0.52 \\
\hline & & Peace* & $1-3$ & 2.34 & 0.54 \\
\hline & & Calm* & $1-3$ & 2.32 & 0.57 \\
\hline & & Total & $\begin{array}{l}14- \\
42\end{array}$ & 34.15 & 5.21 \\
\hline The short QOL-D\# & Nurse & Total & $4-24$ & 22.38 & 4.18 \\
\hline
\end{tabular}




\begin{tabular}{|c|c|c|c|c|c|}
\hline Scale & Respondent & Item & Range & Mean & SD \\
\hline \multirow{2}{*}{\multicolumn{2}{|c|}{$(n=55)$}} & Negative dimension & $3-12$ & 10.72 & 2.01 \\
\hline & & Positive dimension & $7-36$ & 11.68 & 4.02 \\
\hline \multicolumn{6}{|c|}{$\S$ The SM-EOLD-J: Japanese version of symptom management at end-of-life in dementia } \\
\hline \multicolumn{6}{|c|}{$\begin{array}{l}\text { 9The CAD-EOLD-J: Japanese version of comfort assessment in dying with } \\
\text { dementia }\end{array}$} \\
\hline \multicolumn{6}{|c|}{$\begin{array}{l}\text { \#The short QOL-D: short version of the quality of life questionnaire for } \\
\text { dementia }\end{array}$} \\
\hline \multicolumn{6}{|c|}{${ }^{*}$ Reverse coded for calculation of the total score. } \\
\hline
\end{tabular}

The results of convergent validity testing are presented in Table 3. The SM-EOLD-J score was significantly moderately correlated with the negative dimensions of the short QOL-D in nurses $(\gamma=0.587$, $p<0.001)$. No correlation was found between the total scores of the SM-EOLD-J and the positive dimensions of the short QOL-D.

We conducted a confirmatory factor analysis to confirm the nine items of the SM-EOLD-J as similar to the two-factor structure of the original SM-EOLD. The results were GFI $=0.833, \mathrm{CFI}=0.856, \mathrm{RMSEA}=0.130$.

The results of the exploratory factor analysis are shown in Table 5. The SM-EOLD-J was found to have two-factor structures. Pain, shortness of breath, skin breakdown, and depression and anxiety were included in one factor, while fear, calm, agitation, and resistiveness to care were included in the other factor. A confirmatory factor analysis was conducted with the two-factor structure based on the results of the exploratory factor analysis conducted in this study $(\mathrm{GFI}=0.854, \mathrm{CFI}=0.885, \mathrm{RMSEA}=0.114$ ) 
Table 5. Rotated factor structure of the SM-EOLD-J and the

CAD-EOLD-J

\begin{tabular}{|c|c|c|c|c|c|c|}
\hline & \multirow[b]{2}{*}{ Subscales } & \multicolumn{5}{|c|}{ Factor loading } \\
\hline & & Item & $\begin{array}{l}\text { Factor } \\
1\end{array}$ & $\begin{array}{l}\text { Factor } \\
2\end{array}$ & $\begin{array}{l}\text { Factor } \\
3\end{array}$ & $\begin{array}{l}\text { Factor } \\
4\end{array}$ \\
\hline \multirow{11}{*}{$\begin{array}{l}\text { §SSM- } \\
\text { EOLD-J }\end{array}$} & \multirow[t]{3}{*}{ Physical } & Pain & 0.04 & 0.69 & & \\
\hline & & Shortness of breath & 0.05 & 0.50 & & \\
\hline & & Skin breakdown & 0.22 & 0.41 & & \\
\hline & \multirow[t]{8}{*}{ Psychological } & Depression & 0.26 & 0.43 & & \\
\hline & & Anxiety & 0.50 & 0.69 & & \\
\hline & & Fear & 0.54 & 0.38 & & \\
\hline & & Calm & 0.55 & -0.07 & & \\
\hline & & Agitation & 0.78 & 0.38 & & \\
\hline & & $\begin{array}{l}\text { Resistiveness to } \\
\text { care }\end{array}$ & 0.74 & 0.33 & & \\
\hline & & Contribution ratio & 2.11 & 1.94 & & \\
\hline & & $\begin{array}{l}\text { Cumulative } \\
\text { contribution ratio }\end{array}$ & 23.49 & 45.06 & & \\
\hline \multirow{12}{*}{$\begin{array}{l}\text { 9CAD- } \\
\text { EOLD-J }\end{array}$} & \multirow{5}{*}{$\begin{array}{l}\text { Physical } \\
\text { distress }\end{array}$} & Discomfort & 0.73 & 0.09 & 0.27 & -0.27 \\
\hline & & Pain & 0.59 & 0.18 & 0.10 & -0.11 \\
\hline & & Restlessness & 0.67 & 0.27 & 0.13 & 0.00 \\
\hline & & Shortness of breath & 0.47 & 0.14 & 0.45 & 0.10 \\
\hline & & Choking & 0.30 & 0.12 & 0.67 & -0.21 \\
\hline & \multirow[t]{2}{*}{$\begin{array}{l}\text { Dying } \\
\text { symptoms }\end{array}$} & Gurgling & 0.19 & -0.13 & 0.73 & 0.43 \\
\hline & & $\begin{array}{l}\text { Difficulty } \\
\text { swallowing }\end{array}$ & -0.05 & -0.03 & 0.03 & 0.64 \\
\hline & \multirow[t]{4}{*}{ Emotional distress } & Fear & 0.70 & 0.16 & 0.43 & -0.15 \\
\hline & & Anxiety & 0.79 & 0.24 & 0.18 & 0.01 \\
\hline & & Crying & 0.77 & 0.22 & 0.09 & 0.03 \\
\hline & & Moaning & 0.69 & 0.18 & 0.24 & 0.18 \\
\hline & Well-being & Serenity & 0.25 & 0.83 & 0.01 & 0.06 \\
\hline
\end{tabular}




\section{Table 5. Rotated factor structure of the SM-EOLD-J and the CAD-EOLD-J}

\begin{tabular}{|llllll|}
\hline & Peace & 0.22 & 0.91 & -0.02 & -0.06 \\
\cline { 2 - 6 } & Calm & 0.28 & 0.88 & 0.16 & -0.12 \\
\hline & Contribution ratio & 4.05 & 2.61 & 1.59 & 0.82 \\
\hline & $\begin{array}{l}\text { Cumulative } \\
\text { Contribution ratio }\end{array}$ & 28.96 & 47.56 & 58.91 & 64.73 \\
\hline $\begin{array}{l}\text { §The SM-EOLD-J: Japanese version of symptom } \\
\text { management at the end-of-life in dementia }\end{array}$ & & & & \\
$\begin{array}{l}\text { TThe CAD-EOLD-J: Japanese version of comfort assessment in dying with dementia Loadings used } \\
\text { to identify factors are bold texted. }\end{array}$ \\
\hline
\end{tabular}

\section{CAD-EOLD-J}

Scores for each part of the CAD-EOLD-J scales are shown in Table 4. The Cronbach's alpha of the CADEOLD-J rated by nurses was $0.88(n=62)$. The Cronbach's alpha for the CAD-EOLD-J subscales of physical distress, dying symptoms, emotional distress, and well-being were $0.76,0.58,0.87$, and 0.93 , respectively.

The results of convergent validity testing are presented in Table 3. The CAD-EOLD-J score was significantly moderately correlated with the negative dimensions of the short QOL-D score in nurses $(\gamma=$ $0.509, p<0.001)$. However, no correlation was indicated between the CAD-EOLD-J scores and the positive dimensions of the short QOL-D scores in nurses.

We conducted a confirmatory factor analysis to confirm the 14 items of the CAD-EOLD-J as similar to the two-factor structure of the original CAD-EOLD. The results were GFI $=0.812, \mathrm{CFI}=0.929, \mathrm{RMSEA}=0.088$.

The results of the exploratory factor analysis are shown in Table 5. The CAD-EOLD-J was found to have four-factor structures, different to the factors of the original scale. The subscales physical distress and emotional distress were included in one factor, and difficulty swallowing was an independent factor. Shortness of breath, choking, and gurgling were included in one factor, and the subscales for well-being consisted of the same items as the original EOLD scales. A confirmatory factor analysis was conducted with the four-factor structure based on the results of the exploratory factor analysis. The results were GFI $=.839, \mathrm{CFI}=0.943, \mathrm{RMSEA}=0.086$.

\section{Discussion}

SWC-EOLD-J

In this study, the reliability of the SWC-EOLD-J was confirmed by the Cronbach's alpha being above 0.7 (22). Regarding the convergent validity of the EOLD-J scales, a moderate negative correlation was 
observed between the SWC-EOLD-J scores and the DRS-J scores. It can be said that when family members of deceased residents no regret regarding their decision-making in the end-of-life care process, they scored higher in the SWC-EOLD-J, which means they were satisfied with the end-of-life care provided. Based on results from this study, the SWC-EOLD-J could measure the degree of satisfaction in the decision-making process among family members.

The data were collected retrospectively and thus, the answers may have been influenced by selective recall. Therefore, further studies are required on whether the SWC-EOLD-J could be used for evaluation of current care and if the responses are biased by demographic characteristics of family members or availability of services (12).

\section{SM-EOLD-J}

The Cronbach's alpha for the psychological subscale and total score of the SM-EOLD-J, Cronbach's alpha was above 0.7 (22). The Cronbach's alpha for the physical subscale was low (0.58), similar to that of previous studies (14). Therefore, the reliability of the SM-EOLD-J could be confirmed from the results of this study.

The SM-EOLD-J scores were significantly moderately correlated with the negative dimensions of the short QOL-D. This means that nurses gave higher scores in the SM-EOLD when residents' symptoms were good; thus, residents' negative symptoms of dementia may be less evident. It can be said that the convergent validity of the SM-EOLD-J was confirmed. The SM-EOLD-J scores were significantly moderately correlated with the negative dimensions of the short QOL-D. This means that nurses scored higher in the SM-EOLD when residents' symptoms were good; as such, residents' negative symptoms of dementia may be less evident. Further, the nurses scored lower for negative dimensions on the short QOL-D. Thus, it can be said that the convergent validity of the SM-EOLD-J was confirmed. However, there was no correlation between the total scores for positive dimensions of the short QOL-D, which are based on the behavior of the persons with dementia, and scores of the SM-EOLD-J, which are based on the facial expressions and appearances of persons with dementia. The validity of the SM-EOLD-J should be tested using a scale that allows evaluation based on the participants' facial expressions and appearances. However, as there is no scale to examine the facial expressions and appearances of the persons with dementia in Japan, further research is needed to evaluate the convergent validity of the SM-EOLD-J.

The scores of the SM-EOLD-J in this study might have influensed several factors. The scores for pain, depression, and anxiety of the study conducted in New Zealand (23) were lower than the scores in this study. This indicates better symptoms among persons with dementia in this study than among the participants in the New Zealand study. In Japanese nursing homes, people with end-stage dementia are often hospitalized and die in the hospital $(24,25)$. Thus, people with end-stage dementia with severe symptoms may not have died in Japanese nursing homes. Furthermore, the expression and perception of physical and psychological symptoms may have been influenced by the culture of the participants (e.g., stoic response to pain) (26). These several situations may have also affected the factor structure of the SM-EOLD-J. 
Confirmatory factor analysis showed that the fit of the model was not good. In the original EOLD, confirmatory factor analysis was not conducted; therefore, the results cannot be compared with the present results. Due to the small sample size, it is not possible to conclude whether these results are unique to Japan or not. As for the internal consistency coefficient, it could be said that the reliability has been confirmed, but the structural validity has not been sufficiently confirmed, so it will continue to be examined in further studies.

CAD-EOLD-J

The Cronbach's alpha of the CAD-EOLD-J was above 0.7 . Therefore, the reliability of CAD-EOLD-J could be confirmed (22).

The CAD-EOLD-J scores were significantly moderately correlated with the negative dimensions of the short QOL-D. It could be said that when the residents showed fewer signs of discomfort, leading to nurses giving higher scores on the CAD-EOLD-J. Therefore, the convergent validity of the CAD-EOLD-J could be confirmed.

In the results of the exploratory factor analysis, the subscales of physical distress and emotional distress were included as one factor. This result suggests that nurses may be observing physical and psychological symptoms without distinguishing in Japanese nursing homes. Difficulty in swallowing was analyzed as an independent factor. The scores of difficulties swallowing in this study were lower than those in previous studies (23). Moreover, the scores of difficulty in swallowing tended to be lower than the scores for other items of the CAD-EOLD-J. These results may be affected by the factor structure of the CAD-EOLD-J. In the future, it is necessary to further examine whether this result is characteristic of Japan. Confirmatory factor analysis showed that the fit of the model was not good. The CAD-EOLD-J showed a factor structure in which the item for difficulty in swallowing was a single factor, and subscale of Physical symptoms and Dying symptoms were one factor. It is not possible to conclude whether these results are unique to Japan or not, so we will continue to examine the results in future studies.

\section{Limitations}

First, as the participants were referred by the facility managers, the choice of participants may have been biased toward those who had a good relationship with the facility. Second, we did not ask the family members of deceased persons with dementia to complete the SM-EOLD-J and CAD-EOLD-J. The relationship between the assessment of symptoms by the deceased person's family and that of nurses is unknown. Third, persons with dementia living in nursing homes in Japan differ from those in other countries in terms of the medical care they receive at the end of life. It may be necessary to verify whether the results of the EOLD-J scores revealed in this survey reflect trends specific to Japan.

\section{Conclusion}


Through this study, we developed the Japanese version of EOLD-J and confirmed the EOLD-J to be valid and reliable when used in end-stage of person with dementia in Japan. The EOLD-J had a good construct validity and a good internal consistency. However, determination of the factor structure of EOLD-J requires further study.

\section{Abbreviations}

EOLD: end-of-life in dementia; SWC-EOLD: satisfaction with care at end-of-life in dementia; SM-EOLD: symptom management at end-of-life in dementia; CAD-EOLD: Comfort Assessment in Dying with dementia; FAST: Functional Assessment Staging of Alzheimer's Disease scale; QOL-D: quality of life questionnaire for dementia; DRS-J: Japanese Decision Regret Scale; BPSD: behavioral and psychological symptoms of dementia, GFI: goodness of fit index, CFI: comparative fit index, RMSEA: root mean square error of approximation

\section{Declarations}

\section{Ethics Approval and Consent to Participate}

Written informed consent for participation in this study and for the use of the deceased resident's data was obtained from the family members of deceased residents, as well as participating nurses. Research procedures were conducted with the approval of the School of Medicine Research Ethics Committee (Examination number HS2018-199) governing Gunma University affiliates, and that of the management of participating facilities. This study was conducted in accordance with the principles of the Declaration of Helsinki.

\section{Consent for Publication}

Not applicable.

\section{Availability of Data and Materials}

The datasets used and/or analyzed during the current study are available from the corresponding author upon reasonable request.

\section{Competing Interests}

None of the authors had any financial or potential conflicts of interest to declare.

\section{Funding}

The current research was conducted under the auspices of the Sasagawa Health Foundation's 2016 Grant for Research into Hospice and Palliative Care (Grant Number: 2016A-029). Funding from the 
Sasagawa Health Foundation aims at covering costs related to clinical data collection and management. The funder have no role in date analysis nor in publication of results.

\section{Acknowledgments}

We are deeply indebted to the bereaved families, facility managers, and staff who participated in this research. We would also like to express our gratitude to Professor Ladislav Volicer, who lent his support to the development of the EOLD-J scales.

\section{Authors' Contributions}

ST: conception and design of study, performance of statistical analysis, draft of manuscript reading and approval of final manuscript

YU: conception and design of study, performance of statistical analysis, supervision of study, reading and approval of final manuscript

TY: supervision of study, advice on statistical analysis, critical review of manuscript, reading and approval of final manuscript

TS: supervision of study, critical review of manuscript, reading and approval of final manuscript

YC: supervision of study, critical review of manuscript, reading and approval of final manuscript TK: supervision of study, critical review of manuscript, reading and approval of final manuscript.

YT: supervision of study, advice on statistical analysis, critical review of manuscript, reading and approval of final manuscript

HY: Consultation of study design, advice on statistical analysis, critical review of the manuscript, approval of the final version of the manuscript

\section{References}

1. Alzheimer's Disease International. World Alzheimer report; 2018. https://www.alz.co.uk/research/World. Accessed 20 July 2021.

2. The Cabinet Office, Government of Japan. Annual report on the aging society; 2017. https://www8.cao.go.jp/kourei/whitepaper/w-2017/html/gaiyou/s1_2_3.html. Accessed 20 July 2021.

3. Ministry of Health, Labour and Welfare. Toshibu ni okeru ninchishouyuubyouritu to ninntisyouno seikatukinousyougaiheno taiou; 2013. http://www.tsukuba-psychiatry.com/wpcontent/uploads/2013/06/H24Report_Part1.pdf (in Japanese). Accessed 28 July 2021.

4. Van der Steen JT, Radbruch L, Hertogh CM, de Boer ME, Hughes JC, Larkin P, et al. White paper defining optimal palliative care in older people with dementia: a Delphi study and recommendations 
from the European Association for Palliative Care. Palliat Med. 2014;28:197-209. doi:10.1177/0269216313493685.

5. Bessho Y, Deguchi Y, Yasui Y, Kusaka Y, Nagasawa S. Mortality, causes and places of death among the elderly with dementia in a community: results of a ten-year follow-up study. Nihon Koshu Eisei Zasshi. 2005;52:865-73. (in Japanese).

6. Japanese Society of Neurology. Ninchishou shikkan shinryo guidelines. Tokyo: Igaku-Shoin; 2017. (in Japanese).

7. Kuebler KK, Berry PH, Heidrich DE, Beare PG. End-of-life-care: clinical practice guidelines. 1st Japanese ed. Tokyo: Igaku-Shoin Ltd; 2004.

8. Kurokawa Y, Yokojima K, Naganuma A, Matuura M. The actual status of end-of-life care given by nursing and care-giving staff members in nursing care homes. Nursing Journal of Mukogawa Women's University. 2016;1:37-43.

9. Ono M, Hara S. Care provided by specialists during end-of-life care and actual conditions of multidisciplinary collaboration at geriatric health service facilities. Bulletin of Shimane University Faculty of Medicine. 2014;37:9-25.

10. Japanese Nursing Association. Tokubetuyougoroujinhome/Kaigoroujinhokensisetsu ni okeru kangoshokuin jittaichousa houkokusyo; 2016.

https://www.nurse.or.jp/home/publication/pdf/report/2016/kaigojittai.pdf (in Japanese). Accessed 20 July 2021.

11. Miyashita M, Morita T, Sato K, Hirai K, Shima Y, Uchitomi Y. Good death inventory: A measure for evaluating good death from the bereaved family member's perspective. J Pain Symptom Manage. 2008;35:486-98.

12. Miyashita M, Matoba K, Sasahara T, Kizawa Y, Maruguchi M, Abe M, et al. Reliability and validity of the Japanese version of the Support Team Assessment Schedule (STAS-J). Palliat Support Care. 2004;2:379-85.

13. Kiely DK, Volicer L, Teno J, Jones RN, Prigerson HG, Mitchell SL. The validity and reliability of scales for the evaluation of end-of-life care in advanced dementia. Alzheimer Dis Assoc Disord. 2006;20:176-81.

14. Volicer L, Hurley AC, Blasi ZV. Scales for evaluation of end-of-life care in dementia. Alzheimer Dis Assoc Disord. 2001;15:194-200. doi:10.1097/00002093-200110000-00005.

15. Volicer L, Hurley AC. Assessment scales for advanced dementia. Baltimore, MD: Health Professions Press; 2015.

16. Saito T, Chiba Y, Katsuse O, Akihide T, Yamamoto K, Togo T, et al. Retrospective study of the level of satisfaction of family members regarding care for patients with end-stage dementia. Psychiatr Neurol Jpn. 2013;S-560.

17. Sclan SG, Reisberg B. Functional assessment staging (FAST) in Alzheimer's disease: reliability, validity, and ordinality. Int Psychogeriatr. 1992;4;Suppl 1:55-69. doi:10.1017/s1041610292001157. 
18. Tanno K, Bito S, Isobe Y, Takagi Y. Validation of a Japanese version of the decision regret scale. J Nurs Meas. 2016;24:E44-54. doi:10.1891/1061-3749.24.1.E44.

19. Terada S, Oshima E, Ikeda C, Hayashi S, Yokota O, Uchitomi Y. Development and evaluation of a short version of the quality of life questionnaire for dementia. Int Psychogeriatr. 2015;27:103-10. doi:10.1017/S1041610214001811.

20. Norman GR, David L. Streiner. PDQ Statistics Third Edition. Hamilton: B C Decker Inc; 2003.

21. McDonald RP, Ho MHR. Principles and practice in reporting structural equation analyses. Psychol Methods. 2002;7, 1:64-82. doi:10.1037/1082-989x.7.1.64.

22. Streiner DL, Norman GR, Cairney J. Health measurement scales: a practical guide to their development and use. 5th ed. Tokyo: Medical Sciences International Ltd; 2016.

23. Boyd M, Frey R, Balmer D, Robinson J, McLeod H, Foster S, et al. End of life care for long-term care residents with dementia, chronic illness and cancer: prospective staff survey. BMC Geriatr. 2019;19:137. doi:10.1186/s12877-019-1159-2.

24. Koyama T, Sasaki M, Hagiya H, Zamami Y, Funahashi T, Ohshima A, et al. Place of death trends among patients with dementia in Japan: a population-based observational study. Sci Rep.:20235. Sci Rep. 2019;9:20235. doi:10.1038/s41598-019-56388-w.

25. Reyniers T, Deliens L, Pasman HR, Morin L, Addington-Hall J, Frova L, et al. International variation in place of death of older people who died from dementia in 14 European and non-European countries. J Am Med Dir Assoc. 2015;16:165-71. doi:10.1016/j.jamda.2014.11.003.

26. Kagawa-Singer M, Blackhall LJ. Negotiating cross-cultural issues at the end of life: "You got to go where he lives." JAMA. 2001;286:2993-3001. doi:10.1001/jama.286.23.2993.

\section{Figures}

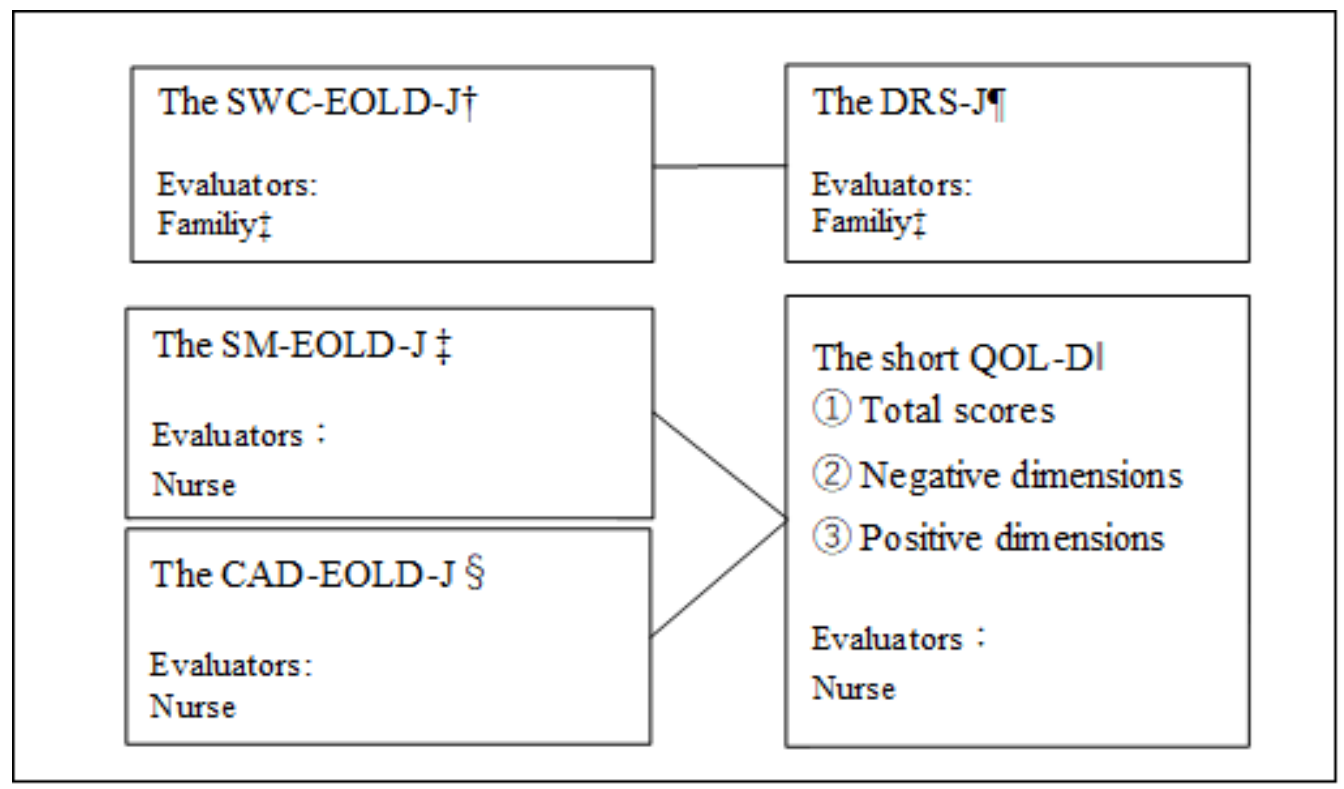

Figure 1 
Convergence validation for End-of-Lie in Dementia scales

‡Family: Family members of the deceased residents

†The SWC-EOLD-J: Japanese version of Satisfaction with care at the end-of-life in dementia $\ddagger$ The SM-EOLD-J: Japanese version of symptom management at the end-of-life in dementia $\S$ The CAD-EOLD-J: Japanese version of comfort assessment in dying with dementia

१The DRS-J: Japanese Decision Regret Scale

\|The short QOL-D: short version of the quality of life questionnaire for dementia 